\title{
Onset and remission of common mental disorders among adults living in temporary housing for three years after the triple disaster in Northeast Japan: comparisons with the general population
}

Norito Kawakami ${ }^{*}$ (D), Maiko Fukasawa ${ }^{1}$, Kiyomi Sakata ${ }^{2}$, Ruriko Suzuki ${ }^{2}$, Hiroaki Tomita ${ }^{3}$, Harumi Nemoto ${ }^{3}$, Seiji Yasumura ${ }^{4}$, Hirooki Yabe ${ }^{4}$, Naoko Horikoshi ${ }^{4}$, Maki Umeda ${ }^{5}$, Yuriko Suzuki ${ }^{6}$, Haruki Shimoda ${ }^{1,2}$, Hisateru Tachimori ${ }^{7}$, Tadashi Takeshima ${ }^{8}$ and Evelyn J. Bromet $^{9}$

\begin{abstract}
Background: People living in temporary housing for long periods after a disaster are at risk of poor mental health. This study investigated the post-disaster incidence and remission of common mental disorders among adults living in temporary housing for the 3 years following the 2011 Great East Japan Earthquake.

Methods: Three years after the disaster, face-to-face interviews were conducted with 1089 adult residents living in temporary housing in the disaster area, i.e., the shelter group, and a random sample of 852 community residents from non-disaster areas of East Japan. The World Health Organization Composite International Diagnostic Interview was used to diagnose DSM-IV mood, anxiety, and alcohol use disorders. Information on demographic variables and disaster experiences was also collected.

Results: Response rates were 49 and $46 \%$ for the shelter group and the community residents, respectively. The incidence of mood/anxiety disorder in the shelter group was elevated only in the first year post-disaster compared to that of the general population. The rate of remission for mood and anxiety disorders was significantly lower in the shelter group than in the community residents. The proportion seeking medical treatment was higher in the shelter group.

Conclusions: The onset of common mental disorders increased in the first year, but then levelled off in the following years among residents in temporary housing after the disaster. Remission from incident post-disaster mental disorders was slower in the shelter group than in the general population. Post-disaster mental health service could consider the greater incidence in the first year and prolonged remission of mental disorders among survivors with a long-term stay in temporary housing after a disaster.
\end{abstract}

Keywords: Natural disasters, Fukushima nuclear accident, Refugees, Incidence, Help-seeking behavior

\footnotetext{
* Correspondence: nkawakami@m.u-tokyo.ac.jp

'Department of Mental Health, Graduate School of Medicine, The University of Tokyo, 7-3-1 Hongo Bunkyo-ku, Tokyo 113-0033, Japan

Full list of author information is available at the end of the article
}

(c) The Author(s). 2020 Open Access This article is licensed under a Creative Commons Attribution 4.0 International License, which permits use, sharing, adaptation, distribution and reproduction in any medium or format, as long as you give appropriate credit to the original author(s) and the source, provide a link to the Creative Commons licence, and indicate if changes were made. The images or other third party material in this article are included in the article's Creative Commons licence, unless indicated otherwise in a credit line to the material. If material is not included in the article's Creative Commons licence and your intended use is not permitted by statutory regulation or exceeds the permitted use, you will need to obtain permission directly from the copyright holder. To view a copy of this licence, visit http://creativecommons.org/licenses/by/4.0/. The Creative Commons Public Domain Dedication waiver (http://creativecommons.org/publicdomain/zero/1.0/) applies to the data made available in this article, unless otherwise stated in a credit line to the data. 


\section{Background}

Natural disasters, such as earthquakes and tsunamis, have a considerable impact on the onset and recurrence of mental disorders [1-5]. Previous studies reported a high prevalence of depressive disorders, anxiety disorder [6], and post-traumatic stress disorder (PTSD) [4]. These prevalence rates were 3-8 times greater compared to non-affected or less-affected populations [4, 7-11]. On the other hand, prevalence of alcohol use disorders usually did not increase after natural disasters [6, 12-14]. Some studies reported that post-disaster prevalence of PTSD sharply declined over time $[11,15]$, while others found the prevalence to remain high years later [16]. Much less attention has been paid to incidence rates of mood, anxiety, and substance use disorders among those with no prior history of psychopathology. In addition, far fewer studies have examined rates of remission, especially from incident post-disaster mental disorders. We are aware of no study that compared change in mental health status during the post-disaster period between disaster survivors and a community population, or factors associated with remission from post-disaster mental disorders. A key predictor of post-disaster mental health is relocation [17-21]. An analysis of data from the WHO World Mental Health Surveys reported that respondents displaced from their homes had a 6.2 times higher prevalence of common mental disorders [22]. However, most studies investigated only the short-term (e.g., within 1 year) impact of relocation.

The Great East Japan Earthquake of March 11, 2011 was a triple disaster involving an earthquake, tsunami, and meltdowns at the Fukushima Dai'ichi nuclear plant, that occurred in coastal areas of three prefectures of the Tohoku region (Iwate, Miyagi, and Fukushima) of Japan. During the disaster and its aftermath, the prolonged stay of survivors in temporary housing became a huge social and public health concern. About 220,000 residents were evacuated from their homes. By 2014, a total of 96,519 still lived in temporary housing. Relocation was consistently reported as an important factor for poor mental health among survivors of the earthquake [23]. In addition, poorer mental health was found among survivors who stayed for several years in prefabricated temporary housing $[24,25]$. A recent study found that depressive symptoms among persons who were moved into prefabricated housing increased two-fold compared to residents remaining in their own homes 2.5 years after the disaster [26]. Psychological distress was particularly higher among survivors who lived in temporary housing for more than 4 years [27]. Our previous study observed an increase in suicide ideation in the first year, but not in the second or third year among survivors living in temporary housing [28]. However, it is still unclear if poorer mental health among survivors who lived longer in temporary housing is attributable to an initial increase of common mental disorders attributable to the disaster, a gradual increase in the incidence in succeeding years due to hardship in staying in temporary housing, or delayed remission from post-disaster common mental disorders. The role of medical treatment for mental disorders after the disaster in explaining poor mental health status of the survivors in temporary housing is also not known, although rates were low after previous natural disasters $[29,30]$.

The objectives of the present study were three-fold. First, we investigated the incidence of post-disaster DSM-IV mental disorders among relocated survivors residing in temporary housing (i.e, the shelter group) for 3 years in disaster areas of the Great East Japan Earthquake, comparing with community residents in East Japan. Second, we investigated the remission and use of medical services for of new-onset post-disaster mental disorders in the shelter group comparing with the community residents. Third, we also conducted regression analyses of the incidence and remission of post-disaster mental disorders on disaster experiences and demographic variables. This study extends our earlier research on suicidal ideation [28] by further focusing of onset and remission of common mental and alcohol use disorders.

\section{Methods \\ Participants \\ Shelter group}

Surveys were conducted with residents living in temporary housing shelters in four municipalities in three coastal areas of the Tohoku region of Japan that were severely damaged by the March 2011 earthquake, tsunami, and nuclear power plant meltdowns. Shelters were selected based on a communication with municipalities in each area. Two shelters were selected in one city of Iwate prefecture (pre-disaster population $\sim 23,000$ ) which lost $7.8 \%$ of its population in the tsunami (1601 died and 207 were lost); interviews were conducted in June-August 2014. In Miyagi prefecture, all six temporary housing residences of one town were selected. The town had a population of 20,419 in 2010; 79 died and 2 were lost due to the tsunami $(0.4 \%$ in all). The survey was also conducted from June to August 2014. In Fukushima prefecture, two municipalities in the coastal area were selected. One had a population of about 71 , 000, with 1105 causalities (1.6\%) due to the tsunami; three temporary housing residences were selected as study sites. The other had a population of about 21,000 , with 541 causalities (2.6\%); all residents were evacuated because of the Fukushima Dai'ichi Nuclear Plant accident. Two temporary residences were selected as study sites. The Fukushima surveys were conducted from October 2013 to February 2014. All residents aged 20 or 
over living in each temporary housing were approached first by a flier, followed by a visit of survey staff. We limited our sample to adults aged 20 or over, because the instrument used in the study was designed to apply to adults. The Committees of Ethics in Research of Human Subjects also allowed us to contact to obtain direct informed consent only for adults aged 20 or over.

\section{General population}

A total of 37 area units were randomly selected from East Japan (excluding the Kanto area), and 1850 residents aged 20-74 years (50 residents per area unit) were randomly selected based on the population registry. These areas were at least $20 \mathrm{~km}$ away from the disaster area and not directly damaged by the earthquake or tsunami, or forced to evacuate because of the meltdowns. These residents were contacted first by a mailed invitation latter, followed by a visit of survey staff. The survey was conducted between August and October, 2014 as part of the World Mental Health Japan Second Survey (WMHJ) [31].

\section{Data collection and ethical consideration}

Participants were the subjects of face-to-face, computerassisted interviews. The instrument used in this study was the Japanese translation of the World Health Organization Composite International Diagnostic Interview (CIDI), version 3.0 [32, 33] developed for trained lay interviewers. The principal investigator (NK) obtained the permission to use the CIDI 3.0 in the surveys from the WHO World Mental Health Survey Executive Committee (see the Supplementary file). Participation was voluntary, and participants were assured of anonymity and confidentiality. Written consent was obtained from each respondent. The authors assert that all procedures contributing to this work comply with the ethical standards of the relevant national and institutional committees on human experimentation and with the Helsinki Declaration of 1975, as revised in 2008. The Committees of Ethics in Research of Human Subjects of the Graduate School of Medicine of The University of Tokyo approved the study protocol and informed consent procedure (No. 10131-(7)).

\section{Assessment of mental disorders}

The CIDI assessment included six DSM-IV [34] diagnoses analysed in this report: major depressive episode (MDE), manic or hypomania episode (MAN), generalized anxiety disorder (GAD), panic disorder (PD), posttraumatic stress disorder (PTSD), and alcohol use disorder (AUD; including both alcohol abuse and dependence). We selected these six disorders from 12 mental disorders assessed in the WMHJ2 survey [31], while we excluded phobic disorders because these disorders have an onset in an early life [35], dysthymia because the diagnosis requires longer duration criteria (i.e., two or more years) [34] and may not be relevant for this 3-year retrospective recall survey, and drug use disorder because of its very low prevalence in Japan [31]. The hierarchy rule was not applied: for instance, GAD was diagnosed even if MDE was present. For MDE, the exclusion of post-bereavement depression (the criteria E) was not used. This was because of lack of precise information to apply the hierarchy rule, as well as for the sake of simplicity. Prevalence of any of the six mental disorders was labelled as ANY.

All diagnoses were assessed for the respondent's lifetime, and then, the age of first onset was asked. For mood (MDE and MAN) and anxiety disorders (GAD, $\mathrm{PD}$, and PTSD), respondents from the disaster area were asked additional questions about the cause of the episode and whether the onset was before or after the disaster. Time of onset of each disorder was then classified into before the Great East Japan Earthquake (hereafter the disaster), the same year of the disaster (2011) (1st year), the 2nd year (2012), and the 3rd year (2013) after the disaster.

For disorders that first occurred after the disaster, duration (years) was calculated based on questions on the maximum length of duration for the new onset disorder. If the disorder was active during the 30 days before the survey, the disorder was classified as on-going; otherwise, the respondent was judged as having remitted.

\section{Disaster experiences}

Respondents were asked about three types of disaster experiences: personal injury (any vs. none), bereavement of family/relative(s) or friend(s)/acquaintance(s), and house damage (any vs. none). Most previous studies of postdisaster mental health used one bereavement variable combining bereavement of family and friends [36-39]. In this study, in order to investigate individual and additive effects of bereavement of family and friends, the bereavement was classified into four groups: no bereavement, bereavement of family/relative, bereavement of friends/acquaintances, and both. Perceived radiation risk was determined from responses to a single item: "For several months after the accident of the Fukushima Dai'ichi Nuclear Power Plant, how much were you worried about the possibility that you and your family members were exposed to radioactivity? (Not at all, a little, to some extent, much, or very much)" Those who responded "much" or "very much" were classified as high perceived radiation risk.

\section{Seeking treatment}

The CIDI included a standard set of questions on seeking treatment for problems with mental health and 
substance [40]. Medical treatment was defined as a visit to psychiatrists or other medical doctors. The proportion of these who sought medical treatment (either psychiatrists or other medical doctors) was calculated among respondents who had a post-disaster mental disorder.

\section{Demographic variables}

Demographic variables assessed during the interview included sex (male vs female), age (20-39, 40-64, and 65+ years old), marital status (married, divorced/separated, widowed, and never married), education (less than high school and high school or higher), and activities of daily living (ADLs) (limited and not limited).

\section{Statistical analyses}

Respondents who had experience of any of the six mental disorders in their lifetime prior to 2011 were excluded from the analyses to investigate the new onset of any of the mental disorders. First, cumulative incidences (i.e., proportions of respondents who had a disorder before a certain point including those who remitted after the onset) of ANY and specific mental disorders among were compared between the shelter sample and the general population sample. The discrete-time proportional hazard model applying the logistic regression [41] was used to estimate odds ratios (ORs) of the incidence in the shelter group compared to the general population, adjusting for sex, age, and education, because the time intervals were discrete. Speed of remission from ANY post-disaster mental disorder was compared between the two samples by using the Kaplan-Meier survival curve (log-rank test for a statistical significance). The median duration (in years) and 95\% CI of the individual mental disorders were also calculated.

In the shelter group, sociodemographic and disasterrelated factors associated with ANY new onset postdisaster mental disorder were investigated with using the discrete-time proportional hazard model. Disorderspecific analyses were conducted for individual mental disorders with 10 or more cases. Among respondents who developed post-disaster mood or anxiety disorders in the shelter group, the association between each of socio-demographic and disaster-related factors and remission from the mental disorder was investigated by using the Kaplan-Meier method with log-rank test.

All variables used in these analyses had no missing response. All statistical analyses were conducted with IBM SPSS Statistics version 22.

\section{Results}

\section{Descriptive characteristics}

A total of 1089 long-term residents of the 13 shelters in the disaster area (the shelter group) were interviewed, including 242 (55.4\%) out of 437 in Iwate, 329 (55.6\%) out of 592 in Miyagi, and 518 (44.0\%) out of 1178 in Fukushima. The overall response rate for shelter respondents was $49.4 \%$. The response rate for the general population was $46.1 \%$ (852 out of 1850). Respondents from the shelters were more likely to be female, older, widowed, have low levels of education, and report disaster-related experiences compared to the general population (Table 1). Shelter respondents had significantly lower rates of most pre-disaster disorders compared to the general population.

\section{Incidence and remission of post-disaster mental disorders} in the shelter group and the general population

In the shelter group and the general population, 3.3 and $0.7 \%$ of respondents, respectively, met criteria for ANY mental disorder in 2011, the year the disaster happened (Table 2). The three-year cumulative incidence until 2013 was 5.6 and $2.7 \%$, respectively. MDE was the most common disorder in the both samples. The three-year cumulative incidence of ANY mental disorder was significantly higher in the shelter group than in the general population $(p=0.010$ for crude analysis and $p=0.002$ after adjusting for sex, age, and education). In terms of specific disorders, compared to the general population, the shelter group had significantly higher cumulative incidences of MDE, GAD, and PTSD $(p<0.01)$, but not MAN, PD, or AUD $(p>0.05)$.

The proportion of individuals who had not remitted from ANY post-disaster mood and anxiety disorders (excluding alcohol use disorder) was higher in the shelter group $(n=$ $57)$ than in the general population $(n=14)$ (log-rank test, chi-square $=17.9, \mathrm{df}=1, p<0.001)$ (Fig. 1). The median durations of post-disaster ANY were 2.00 years (standard error [SE], 0.36) and 0.25 years (SE, 0.10) in the shelter group and the general population, respectively.

\section{Seeking treatment for post-disaster mental disorders}

The proportions of individuals who visited psychiatrists or other physicians among people with post-disaster ANY were greater in the shelter group (42.6\%, 26 of 61 cases) than in the general population $(17.4 \%, 4$ of 23 cases) (Fisher exact test, $p=0.011$ ). The proportions of those seeking treatment for MDE were 39.5\% (17 of 43 cases) for the shelter group and 30.8\% (4 of 13 cases) for the general population (Fisher exact test, $p=0.339$ ). The proportion of treatment for PTSD (9.1\%) was lower than for the other disorders in the shelter group, while no comparison was possible between the two groups because of no post-disaster cases with PTSD in the general population. None of respondent with post-disaster AUD ( $n=5$ for the disaster areas; $n=9$ for the general population) had visited psychiatrists or other physicians. 
Table 1 Characteristics of the shelter group and the general population sample 3 year after the Great East Japan Earthquake in 2011

\begin{tabular}{|c|c|c|c|c|c|}
\hline & \multicolumn{2}{|c|}{ Shelter group $(n=1089)$} & \multicolumn{2}{|c|}{ General population in east Japan $(n=852)$} & \multirow{2}{*}{$\begin{array}{l}p \text { for } \\
\text { difference }^{a}\end{array}$} \\
\hline & $\bar{n}$ & $\%$ & $\bar{n}$ & $\%$ & \\
\hline Sex (females) & 667 & 61.2 & 438 & 51.4 & $<0.010$ \\
\hline \multicolumn{6}{|l|}{ Age, years } \\
\hline 20-39 & 100 & 9.2 & 233 & 27.3 & \multirow[t]{3}{*}{$<0.001$} \\
\hline $40-64$ & 357 & 32.8 & 427 & 50.1 & \\
\hline $65+$ & 632 & 58.0 & 192 & 22.5 & \\
\hline \multicolumn{6}{|l|}{ Marital status } \\
\hline Married & 628 & 57.7 & 615 & 72.2 & \multirow[t]{4}{*}{$<0.001$} \\
\hline Divorced/separated & 75 & 6.9 & 46 & 5.4 & \\
\hline Widowed & 266 & 24.4 & 39 & 4.6 & \\
\hline Never married & 120 & 11.0 & 152 & 17.8 & \\
\hline Education (high school or higher) & 653 & 60.0 & 788 & 92.5 & $<0.001$ \\
\hline ADL (limited) & 57 & 5.2 & 1 & 0.1 & $<0.001$ \\
\hline \multicolumn{6}{|l|}{ Disaster experiences } \\
\hline Own injury (any) & 53 & 4.9 & 1 & 0.1 & $<0.001$ \\
\hline \multicolumn{6}{|l|}{ Bereavement during the disaster } \\
\hline None & 450 & 41.3 & 835 & 98.0 & $<0.001$ \\
\hline Family/relative & 313 & 28.7 & 5 & 0.6 & $<0.001$ \\
\hline Friend/acquaintance & 128 & 11.8 & 12 & 1.4 & $<0.001$ \\
\hline Both & 198 & 18.2 & - & - & $<0.001$ \\
\hline House damage (any) & 877 & 80.5 & 23 & 2.7 & $<0.001$ \\
\hline Radiation anxiety (high) & 326 & 29.9 & 118 & 13.8 & $<0.001$ \\
\hline \multicolumn{6}{|c|}{ Lifetime prevalence of mental disorders before the disaster } \\
\hline Any ${ }^{\mathrm{b}}$ & 79 & 7.3 & 157 & 18.4 & $<0.001$ \\
\hline Major depressive episode & 13 & 1.2 & 32 & 3.8 & $<0.001$ \\
\hline Manic episode & 1 & 0.1 & 2 & 0.2 & 0.587 \\
\hline GAD & 6 & 0.6 & 16 & 1.9 & 0.008 \\
\hline Panic disorder & 4 & 0.4 & 4 & 0.5 & 0.736 \\
\hline PTSD & 4 & 0.4 & 3 & 0.4 & 1.000 \\
\hline Alcohol use disorder & 64 & 5.9 & 123 & 14.4 & $<0.001$ \\
\hline
\end{tabular}

${ }^{a}$ Chi-square test for age and marital status; otherwise, Fisher exact test

${ }^{b}$ Any of six mental disorders including major depressive episode, manic episode, generalized anxiety disorder (GAD), panic disorder, post-traumatic stress disorder (PTSD), and alcohol use disorder

Disaster risk factors associated with onset and remission of post-disaster mental disorders in the shelter group In the shelter group, being divorced/separated $(O R=$ $3.00, \quad 95 \% C I=1.35-6.68, \quad p=0.007)$, personal injury $(O R=6.10,95 \% C I=2.97-12.55, p<0.001)$, and bereavement of both family/relative and friend $(O R=2.73,95 \%$ $C I=1.13,6.60, p=0.026)$ were significantly associated with post-disaster onset of ANY disorder (Table 3). In the disorder-specific analyses (data available upon request), it was found that female sex $(O R=2.41,95 \% C I=$ $1.12-5.17, p=0.024)$, being never married $(O R=4.05$, $95 \% C I=1.42-11.53, p=0.009)$, personal injury $(O R=$ $8.84,95 \% C I=3.91-20.00, p<0.001)$, and bereavement of both family/relative and friends $(O R=3.41,95 \% C I=$ $1.23-9.42, p=0.018)$ were significantly associated with the onset of MDE. Personal injury $(O R=8.65,95 \% C I=$ $1.95-38.42, p=0.005)$ and bereavement of both family/ relative and friend $(O R=22.53,95 \% C I=1.67-303.83$, $p=0.019$ ) were significantly associated with PTSD. Personal injury was the only disaster risk factor significantly associated with the onset of GAD $(O R=5.98,95 \% C I=$ 2.08-17.21, $p=0.001$ ).

None of the demographic and disaster-related factors were significantly associated with the remission from post-disaster mood and anxiety disorders among 57 respondents who had any post-disaster mood and anxiety 
Table 2 Cumulative incidence of mental disorders among respondents without pre-disaster mental disorders following the Great East Japan Earthquake $2011^{\text {a }}$

\begin{tabular}{|c|c|c|c|c|c|c|c|}
\hline & $\begin{array}{l}\text { ANY } \\
\% \text { (SE) }\end{array}$ & $\begin{array}{l}\text { MDE } \\
\%(S E)\end{array}$ & $\begin{array}{l}\text { MAN } \\
\%(\mathrm{SE})\end{array}$ & $\begin{array}{l}\text { GAD } \\
\%(S E)\end{array}$ & $\begin{array}{l}\mathrm{PD} \\
\%(\mathrm{SE})\end{array}$ & $\begin{array}{l}\text { PTSD } \\
\%(S E)\end{array}$ & $\begin{array}{l}\text { AUD } \\
\%(\mathrm{SE})\end{array}$ \\
\hline \multicolumn{8}{|l|}{ Shelter group $(n=1010)^{\mathrm{b}}$} \\
\hline Post disaster year 1 & $3.3(0.6)$ & $2.9(0.5)$ & $0.2(0.1)$ & $1.4(0.4)$ & $0.1(0.1)$ & $0.6(0.2)$ & $0.1(0.1)$ \\
\hline Post disaster year 2 & $4.8(0.7)$ & $4.1(0.6)$ & $0.2(0.1)$ & $1.9(0.4)$ & $0.1(0.1)$ & $1.0(0.3)$ & $0.2(0.1)$ \\
\hline Post disaster year 3 & $5.6(0.7)$ & $4.3(0.6)$ & $0.2(0.1)$ & $2.3(0.5)$ & $0.2(0.1)$ & $1.0(0.3)$ & $0.4(0.2)$ \\
\hline \multicolumn{8}{|l|}{ General population $(n=695)^{b}$} \\
\hline Post disaster year 1 & $0.7(0.3)$ & $0.3(0.2)$ & $0(-)$ & $0.1(0.1)$ & $0(-)$ & $0(-)$ & $0.4(0.2)$ \\
\hline Post disaster year 2 & $1.3(0.4)$ & $0.6(0.3)$ & $0(-)$ & $0.1(0.1)$ & $0(-)$ & $0(-)$ & $0.7(0.3)$ \\
\hline Post disaster year 3 & $2.7(0.6)$ & $1.4(0.5)$ & $0.1(0.1)$ & $0.3(0.2)$ & $0(-)$ & $0(-)$ & $1.2(0.4)$ \\
\hline Log-rank $p$ for group difference & 0.010 & 0.006 & 0.521 & 0.001 & 0.240 & 0.006 & 0.072 \\
\hline \multicolumn{8}{|c|}{ Cox hazard model adjusted for sex, age, and educational attainment: } \\
\hline Adjusted hazard ratio & 2.23 & 2.46 & 4.65 & 11.13 & NC & NC & 0.60 \\
\hline $95 \% \mathrm{Cl}$ & $(1.33-3.75)$ & $(1.27-4.76)$ & $(0.45-48.09)$ & $(2.55-48.65)$ & & & $(0.17-2.08)$ \\
\hline p & 0.002 & 0.007 & 0.299 & 0.001 & & & 0.421 \\
\hline
\end{tabular}

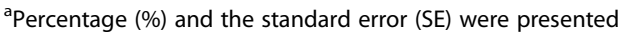

${ }^{\mathrm{b}}$ Respondents with any disorder before the disaster were excluded. Any disorder includes any of six mental disorders including major depressive episode (MDE), manic episode (MAN), generalized anxiety disorder (GAD), panic disorder (PD), post-traumatic stress disorder (PTSD), and alcohol use disorder (AUD) NC not calculated

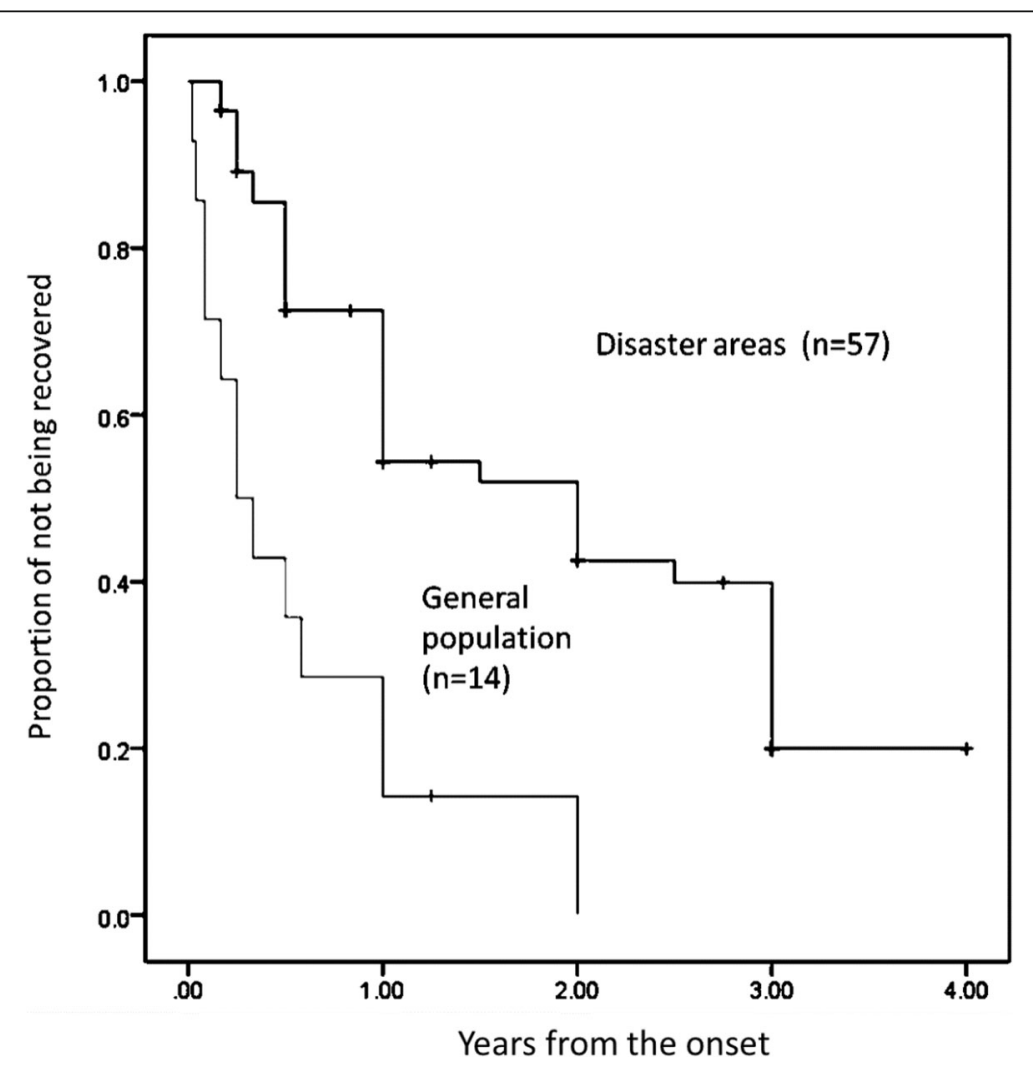

Fig. 1 Remission from post-disaster DSM-IV mood and anxiety disorders in the shelter group and in the general population. A significant difference in the remission was observed between respondents in the shelter group and the general population (Logrank test, $p<0.001)$ 
Table 3 Factors associated with post-disaster mental disorders in the shelter group during 3 years after the Great East Japan Earthquake $2011^{\text {a }}$

\begin{tabular}{|c|c|c|c|c|}
\hline \multirow{2}{*}{$\begin{array}{l}\text { Variables } \\
\text { Sex (female) }\end{array}$} & \multirow{2}{*}{$\begin{array}{l}O R^{b} \\
0.69\end{array}$} & \multicolumn{2}{|c|}{$\begin{array}{l}95 \% \mathrm{Cl} \\
\text { (low to high) }\end{array}$} & \multirow{2}{*}{$\begin{array}{l}p \\
0.235\end{array}$} \\
\hline & & 0.38 & 1.27 & \\
\hline \multicolumn{5}{|l|}{ Age, years } \\
\hline $20-39$ & 1.00 & & & \\
\hline $40-64$ & 1.56 & 0.57 & 4.31 & 0.388 \\
\hline $65+$ & 1.38 & 0.46 & 4.17 & 0.570 \\
\hline Education (high school or higher) & 1.12 & 0.61 & 2.04 & 0.721 \\
\hline \multicolumn{5}{|l|}{ Marital status } \\
\hline Married & 1.00 & & & \\
\hline Divorced/separated & 3.00 & 1.35 & 6.68 & 0.007 \\
\hline Widowed & 0.90 & 0.45 & 1.82 & 0.778 \\
\hline Never married & 1.90 & 0.75 & 4.82 & 0.174 \\
\hline Current ADL (limited) & 0.55 & 0.12 & 2.39 & 0.423 \\
\hline Personal injury (yes) & 6.10 & 2.97 & 12.55 & $<0.001$ \\
\hline \multicolumn{5}{|l|}{ Bereavement during the disaster } \\
\hline None & 1.00 & & & \\
\hline Family/relative & 0.94 & 0.45 & 1.95 & 0.867 \\
\hline Friend/acquaintance & 1.87 & 0.80 & 4.37 & 0.150 \\
\hline Both & 2.73 & 1.13 & 6.60 & 0.026 \\
\hline Home damage (yes) & 2.12 & 0.90 & 5.00 & 0.085 \\
\hline Radiation risk perception (high) & 1.46 & 0.80 & 2.68 & 0.217 \\
\hline \multicolumn{5}{|l|}{ Study area (prefecture) } \\
\hline Iwate & 1.00 & & & \\
\hline Miyagi & 0.80 & 0.31 & 2.04 & 0.638 \\
\hline Fukushima & 1.75 & 0.72 & 4.26 & 0.216 \\
\hline
\end{tabular}

a Discrete proportional hazard model was used. Among 1010 respondents, 61 developed any of six post disaster mental disorders (major depressive episode, manic episode, generalized anxiety disorder, panic disorder, PTSD, and alcohol use disorder)

${ }^{\mathrm{b}} \mathrm{OR}$ odds ratio

disorder (Kaplan-Meier method with the log-rank test, $p>0.05)$. (data available upon request).

\section{Post-hoc power analysis}

For the comparison of the three-year cumulative incidences of post-disaster mental disorders (z-test), we observed an about two-fold difference between the shelter sample (5.6\% among 1010 respondents) and the general population (2.7\% among 695 respondents). The statistical power to detect the difference with two-tailed $p=0.05$ was estimated as 0.85 .For the comparison of the remission of post-disaster mental disorders (log-rank test), for instance, at one-year, we observed median survival durations in the shelter sample (2.00 year among 57 respondents) and the general population ( 0.25 years among 14 respondents). An estimation of the statistical power to detect the difference with two-tailed $p=0.05$ was 0.91 .

\section{Discussion}

Among the survivors living in temporary housing for 3 years or longer after the 2011 Great East Japan Earthquake, $3.3 \%$ experienced a new onset of a common mental disorder in the first year (in 2011), five times higher than the general population. However, the incidence levelled off in the second and third years and became similar to that of the general population. On the other hand, remission from post-disaster mood and anxiety disorders was prolonged in the shelter group compared to the general population, even though the proportion seeking medical treatment was greater in the shelter group. These findings suggest that poor mental health among disaster survivors who stayed in temporary housing for several years is in part attributable to slow remission from common mental disorders despite greater use of medical services.

About 1 in 18 respondents living in the shelter group developed a new mental disorder during the three-year period after the disaster. This three-year incidence was about two times higher than in the general population. For individual disorders, the incidences were significantly higher for MDE, GAD and PTSD, but not for AUD, as has been reported in some previous postdisaster studies $[4,6-11]$. The first-year incidence in the shelter group was particularly higher compared to that in the general population. However, there were few delayed onset cases in the second and third years. This is consistent with previous post-disaster studies of mixed samples of displaced and non-displaced survivors $[6,8$, 10, 11] . The present finding replicates our previous finding on incident suicide ideation from the same sample [28], and extends this pattern into common mental disorders.

In the shelter group, those who had been injured were more likely to develop ANY and specific mental disorders (MDE, GAD, and PTSD). Bereavement of both family and friends was significantly associated with ANY as well as MDE and PTSD. These findings are consistent with previous symptom-based studies [1, 4, 38, 42]. In the shelter group, the association of bereavement of friends with mental disorders was slightly larger than that of family. This may be partly because most bereavement cases lost older family members [43] and thus might have accepted their deaths more readily. In addition, respondents who lost their family may receive more sympathy and support from the community.

The present study found that remission from postdisaster mood and anxiety disorders was delayed in the shelter group compared to the general population. The median duration of morbidity was 2.0 years in the shelter 
group. Previous studies of survivors who were relocated to temporary housing for two or 3 years consistently reported elevated levels of psychological distress after the Great East Japan Earthquake [24-27] . Poor mental health in this group may partly be attributable to the slow time to remission from post-disaster common mental disorders. Possible factors underlying the prolonged remission may include reduced physical activity and impaired physical function in this group [44, 45] that may prevent a faster remission from depression and anxiety disorders [46]. The other possibility is that remission was delayed because of deteriorating physical health due to conditions of the temporary housing [24, 47]. Lower job opportunities among people living in the temporary housing may also delay the remission from mental disorders [48]. Other disadvantages in social, economic, and working life may also affect remission among people who still lived in the temporary housing 3 years after the disaster compared to those who left earlier. Future studies need to disentangle the various stressors inherent in temporary housing to identify adversities that are modifiable.

The proportion of respondents seeking medical treatment among those who suffered a post-disaster mental disorder was higher in the shelter group than in the general population. In a previous report, survivors of disasters were reluctant to use mental health services [30]. The present finding is attributable to post-disaster mental health measures taken by the government, local communities, and non-profit organizations $[43,49,50]$. For instance, in most disaster areas, community health nurses and other field workers/volunteers closely monitored the mental and physical health of people living in temporary housing after the disaster, and referred them to medical treatment if they observed a problem. It is puzzling that the shelter group experienced a prolonged remission from mental disorders, despite a higher treatment rate. However, it is difficult to draw conclusions on the effectiveness of medical treatment from this observational study. Further well-designed research is needed to explore its effectiveness. Also, the treatment rate was lower for PTSD and AUD. Associated behavioural characteristics, such as social withdrawal, may prevent people with these disorders from accessing medical treatment. In addition to providing medical treatment, psychological treatment and psychosocial support including and group peer support may be beneficial.

The present study did not find disaster-related factors that were significantly associated with the delay in remission of post-disaster mood and anxiety disorders in the shelter group. However, this may be due to the small number of respondents who developed these disorders in the shelter group. It may have a merit to investigate factors associated with the remission separately from factors associated with the incidence in disaster survivors under different social and living situations. Factors associated with the remission should be investigated further in a large scale prospective study of disaster survivors.

\section{Limitations}

Several limitations should be noted in the context of the present study. First, the findings should be generalized with caution since study sites of the shelter group were based on the availability of local investigators and the willingness of the director to participate in the study. Thus, the shelters could not be selected randomly. However, the surveys covered all three prefectures affected by the disaster. Second, the selection biases should be considered. The cumulative incidence in the present study may be underestimated because some residents who developed severe mental disorders may have been hospitalized or institutionalized. The cumulative incidence may also have been overestimated because disaster survivors with socioeconomic disadvantages may stay in temporary housing longer, which could result in a higher incidence. In addition, the response rate of the study was not high. A previous study reported that the response rate may not be strongly associated with the prevalence estimates [51]. However, it was possible that residents in temporary housing who had mental disorders were reluctant to participate in the study. The cumulative incidences could be lower than the whole shelter samples and community residents because we selected respondents who had no mental disorder before the disaster. Third, the findings are subject to recall bias. Pre-disaster prevalence of mental disorders was much lower for the shelter group than the general population, possibly because the affected areas were located in rural coastal areas where the prevalence of mental disorders is lower in general [52]. However, a reporting bias due to social desirability may affect the responses to CIDI questions among the shelter sample. The differential reporting of the pre-disaster prevalence and post-disaster incidence of mental disorders in the two samples may affect the findings. Fourth, respondents in the shelter group may report post-disaster mental disorders more frequently because the disorder onset was closely related to a memory anchor, that is, the disaster. This may have been reflected in the low prevalence of pre-disaster mental disorders in the disaster area sample. Furthermore, in analyses of factors associated with mental disorders, respondents with mental disorders may have reported more disaster-related events, owing in part to cognitive issues. Fifth, the determination of the year of onset of mental disorders depended on the information on current age and age of onset. The accuracy could thus be off by 1 year in some cases. However, the interview 
contained specific probes to maximize accuracy of dating onset of each mental disorder. Sixth, possible confounding factors should be considered. Sex, age, and educational attainment were adjusted in the analyses, but it may not be enough to make the samples from the disaster areas and the general population comparable. Indicators of current socioeconomic status, such as household income and employment, were not adjusted. Pre-disaster socioeconomic indicators other than education were not measured in this study. Future studies should include this information. Finally, the sample size and the number of cases of individuals who developed mental disorders were small. Thus, some of the observed differences should be interpreted carefully, and the study may have been underpowered to detect significant differences especially for the individual disorders. Likewise, we could not compare the remission between the two groups for each disorder, which made the interpretation of the findings difficult. A large scale prospective study of disaster survivors is needed to overcome these weaknesses of the present study.

\section{Conclusions}

The onset of common mental disorders increased in the first year, but then levelled off in the following years among residents in temporary housing after the triple disaster in the Tohoku area of Japan in 2011. The overall remission from post-disaster mood and anxiety disorders was slower in the shelter residents than in the general population. Post-disaster mental health service should consider a greater incidence in the first year and prolonged remission of mental disorders among survivors with a long-term stay in temporary housing after a disaster.

\section{Supplementary information}

Supplementary information accompanies this paper at https://doi.org/10. 1186/s12889-020-09378-x.

\section{Additional file 1:.}

\section{Abbreviations}

PTSD: Post-traumatic stress disorder; DSM-IV: Diagnostic and Statistical Manual of Mental Disorders, fourth edition; WMHJ2: The World Mental Health Japan Second Survey; CIDI: Composite International Diagnostic Interview; MED: Major depressive episode; MAN: Manic or hypomania episode; GAD: Generalized anxiety disorder; PD: Panic disorder; AUD: Alcohol use disorder; ANY: Any of the six mental disorders; ADLs: Activities of daily living; OR: Odds ratio; SE: Standard error

\section{Acknowledgements}

The survey was carried out in conjunction with the World Health Organization World Mental Health (WMH) Survey Initiative, which is supported by the National Institute of Mental Health (NIMH; R01 MH070884 and R01 MH093612-01), the John D. and Catherine T. MacArthur Foundation, the Pfizer Foundation, the US Public Health Service (R13-MH066849, R01MH069864, and R01 DA016558), the Fogarty International Center (FIRCA R03TW006481), the Pan American Health Organization, Eli Lilly and Company,
Ortho-McNeil Pharmaceutical, GlaxoSmithKline, and Bristol-Myers Squibb. We thank the staff of the WMH Data Collection and Data Analysis Coordination Centres for assistance with instrumentation, fieldwork, and consultation on data analysis. A complete list of all within-country and cross-national WMH publications can be found at http://www.hcp.med.harvard.edu/wmh/.

\section{Authors' contributions}

NK was responsible for designing and conducting the study, statistical analysis and writing the manuscript. MF, KS, RS, HT, HN, SY, HY, NH, MU, YS, $H S, H T, T T$, and EB contributed to designing and conducting the survey, and commenting on the manuscript draft. All authors critically reviewed and approved the final version of the manuscript.

\section{Funding}

The present study was supported by the 2014 Grant for Research on Health Security Control Research (H25-KENKI-SHITEI-001) and the 2014 Grant for Psychiatric and Neurological Diseases and Mental Health (H25-SEISHIN-IPPA $\mathrm{N}$-006) from the Japan Ministry of Health, Labour, and Welfare; the Study of the Health Effects of Radiation organized by the Japanese Ministry of the Environment 2013; and the Special Project Research of the Tohoku University International Research Institute for Disaster Science 2014. None of the funders had any role in the design, analysis, interpretation of results, or preparation of this paper.

\section{Availability of data and materials}

The datasets used and analysed during the current study are available from the corresponding author on reasonable request.

\section{Ethics approval and consent to participate}

The Committees of Ethics in Research of Human Subjects of the Graduate School of Medicine of The University of Tokyo approved the study protocol and informed consent procedure (No. 10131-(7)). Written consent was obtained from each respondent. Participation was voluntary, and participants were assured of anonymity and confidentiality. The authors assert that all procedures contributing to this work comply with the ethical standards of the relevant national and institutional committees on human experimentation and with the Helsinki Declaration of 1975, as revised in 2008.

Consent for publication

Not applicable.

\section{Competing interests}

The authors declare that they have no competing interests.

\section{Author details}

${ }^{1}$ Department of Mental Health, Graduate School of Medicine, The University of Tokyo, 7-3-1 Hongo Bunkyo-ku, Tokyo 113-0033, Japan. ²Department of Hygiene and Preventive Medicine, Iwate Medical University School of Medicine, 1-1-1 Idaidori, Yahaba-cho, Shiwa-gun, Iwate 028-3694, Japan. ${ }^{3}$ Department of Disaster Psychiatry, International Research Institute of Disaster Science (IRIDeS), Tohoku University, 2-1 Seiryo-machi, Aoba-ku, Sendai, Miyagi 980-8573, Japan. ${ }^{4}$ Fukushima Medical University School of Medicine, 1 Hikariga-oka, Fukushima, Fukushima 960-1295, Japan. ${ }^{5}$ Research Institute of Nursing Care for People and Community, University of Hyogo, 13-71 Kitaoji, Akashi, Hyogo 673-8588, Japan. ${ }^{6}$ National Institute of Mental Health, National Center of Neurology and Psychiatry, 4-1-1 Ogawa-Higashi, Kodaira, Tokyo 187-8553, Japan. ${ }^{7}$ Department of Clinical Epidemiology, Translational Medical Center, National Center of Neurology and Psychiatry, 4-1-1 Ogawa-Higashi, Kodaira, Tokyo 187-8553, Japan. ${ }^{8}$ Kawasaki City Center for Mental Health and Welfare, 1 Miyamoto-cho, Kawasaki-ku, Kawasaki, Kanagawa 210-8577, Japan. ${ }^{9}$ Department of Psychiatry, Stony Brook University, 100 Nicolls Road, Stony Brook, NY 11794, USA.

Received: 20 December 2019 Accepted: 12 August 2020

Published online: 20 August 2020

\section{References}

1. Galea S, Nandi A, Vlahov D. The epidemiology of post-traumatic stress disorder after disasters. Epidemiol Rev. 2005;27:78-91. 
2. Ghodse H, Galea S. Tsunami: understanding mental health consequences and the unprecedented response. Int Rev Psychiatry. 2006;18(3):289-97.

3. Goldmann E, Galea S. Mental health consequences of disasters. Annu Rev Public Health. 2014;35:169-83.

4. Neria Y, Nandi A, Galea S. Post-traumatic stress disorder following disasters: a systematic review. Psychol Med. 2008;38(4):467-80.

5. Parker G, Lie D, Siskind DJ, Martin-Khan M, Raphael B, Crompton D, Kisely S. Mental health implications for older adults after natural disasters - a systematic review and meta-analysis. Int Psychogeriatr. 2016;28(1):11-20.

6. Fergusson DM, Horwood LJ, Boden JM, Mulder RT. Impact of a major disaster on the mental health of a well-studied cohort. JAMA Psychiatry. 2014;71(9):1025-31.

7. Beaglehole B, Mulder RT, Frampton CM, Boden JM, Newton-Howes G, Bell CJ. Psychological distress and psychiatric disorder after natural disasters: systematic review and meta-analysis. Br J Psychiatry. 2018;213(6):716-22.

8. Basoglu M, Kilic C, Salcioglu E, Livanou M. Prevalence of posttraumatic stress disorder and comorbid depression in earthquake survivors in Turkey: an epidemiological study. J Trauma Stress. 2004;17(2):133-41.

9. Bonde JP, Utzon-Frank N, Bertelsen M, Borritz M, Eller NH, Nordentoft M, Olesen K, Rod NH, Rugulies R. Risk of depressive disorder following disasters and military deployment: systematic review with meta-analysis. $\mathrm{Br} \mathrm{J}$ Psychiatry. 2016.

10. Carr VJ, Lewin TJ, Webster RA, Kenardy JA, Hazell PL, Carter GL. Psychosocial sequelae of the 1989 Newcastle earthquake: II. Exposure and morbidity profiles during the first 2 years post-disaster. Psychol Med. 1997;27(1):16778 .

11. van Griensven F, Chakkraband ML, Thienkrua W, Pengjuntr W, Lopes Cardozo B, Tantipiwatanaskul P, Mock PA, Ekassawin S, Varangrat A, Gotway $C$, et al. Mental health problems among adults in tsunami-affected areas in southern Thailand. JAMA. 2006;296(5):537-48.

12. Keyes KM, Hatzenbuehler ML, Grant BF, Hasin DS. Stress and alcohol: epidemiologic evidence. Alcohol Res. 2012;34(4):391-400.

13. Keyes KM, Hatzenbuehler ML, Hasin DS. Stressful life experiences, alcohol consumption, and alcohol use disorders: the epidemiologic evidence for four main types of stressors. Psychopharmacology. 2011;218(1):1-17.

14. North CS, Ringwalt CL, Downs D, Derzon J, Galvin D. Postdisaster course of alcohol use disorders in systematically studied survivors of 10 disasters. Arch Gen Psychiatry. 2011;68(2):173-80

15. Carr VJ, Lewin TJ, Kenardy JA, Webster RA, Hazell PL, Carter GL, Williamson M. Psychosocial sequelae of the 1989 Newcastle earthquake: III. Role of vulnerability factors in post-disaster morbidity. Psychol Med. 1997;27(1):179-90.

16. Onder E, Tural U, Aker T, Kilic C, Erdogan S. Prevalence of psychiatric disorders three years after the 1999 earthquake in Turkey: Marmara earthquake survey (MES). Soc Psych Psych Epid. 2006:41(11):868-74.

17. Fussell E, Lowe SR. The impact of housing displacement on the mental health of low-income parents after hurricane Katrina. Soc Sci Med. 2014;113: 137-44

18. Kuwabara H, Shioiri T, Toyabe S, Kawamura T, Koizumi M, Ito-Sawamura M, Akazawa K, Someya T. Factors impacting on psychological distress and recovery after the 2004 Niigata-Chuetsu earthquake, Japan: communitybased study. Psychiatry Clin Neurosci. 2008;62(5):503-7.

19. Ranasinghe PD, Levy BR. Prevalence of and sex disparities in posttraumatic stress disorder in an internally displaced Sri Lankan population 6 months after the 2004 tsunami. Disaster Med Public Health Prep. 2007;1(1):34-41 discussion 41-33.

20. Sastry N, VanLandingham M. One year later: mental illness prevalence and disparities among New Orleans residents displaced by hurricane Katrina. Am J Public Health. 2009;99(Suppl 3):S725-31.

21. Uscher-Pines $L$. Health effects of relocation following disaster: a systematic review of the literature. Disasters. 2009;33(1):1-22.

22. Bromet EJ, Atwoli L, Kawakami N, Navarro-Mateu F, Piotrowski P, King AJ, Aguilar-Gaxiola S, Alonso J, Bunting B, Demyttenaere K, et al. Post-traumatic stress disorder associated with natural and human-made disasters in the world mental health surveys. Psychol Med. 2017;47(2):227-41.

23. Ando S, Kuwabara H, Araki T, Kanehara A, Tanaka S, Morishima R, Kondo S, Kasai K. Mental health problems in a community after the great East Japan earthquake in 2011: a systematic review. Harv Rev Psychiatry. 2017;25(1):1528 .

24. Murakami A, Sugawara Y, Tomata Y, Sugiyama K, Kaiho Y, Tanji F, Tsuji I. Association between housing type and $\gamma$-GTP increase after the great East Japan earthquake. Soc Sci Med. 2017;189:76-85.
25. Nagata S, Matsunaga A, Teramoto C. Follow-up study of the general and mental health of people living in temporary housing at 10 and 20 months after the great East Japan earthquake. Jpn J Nurs Sci. 2015;12(2):162-5.

26. Sasaki $Y$, Aida J, Tsuji T, Miyaguni $Y$, Tani $Y$, Koyama S, Matsuyama $Y$, Sato $Y$, Tsuboya T, Nagamine $Y$, et al. Does type of residential housing matter for depressive symptoms in the aftermath of a disaster? Insights from the great East Japan earthquake and tsunami. Am J Epidemiol. 2018;187(3):455-64.

27. Tanji F, Tomata Y, Sekiguchi T, Tsuji I. Period of residence in prefabricated temporary housing and psychological distress after the great East Japan earthquake: a longitudinal study. BMJ Open. 2018;8(5):e018211.

28. Xu Q, Fukasawa M, Kawakami N, Baba T, Sakata K, Suzuki R, Tomita H, Nemoto $H$, Yasumura S, Yabe $H$, et al. Cumulative incidence of suicidal ideation and associated factors among adults living in temporary housing during the three years after the great East Japan earthquake. J Affect Disord. 2018;232:1-8.

29. North CS, Pfefferbaum B. Mental health response to community disasters: a systematic review. JAMA. 2013;310(5):507-18.

30. Rodriguez JJ, Kohn R. Use of mental health services among disaster survivors. Curr Opin Psychiatry. 2008;21(4):370-8.

31. Ishikawa H, Tachimori H, Takeshima T, Umeda M, Miyamoto K, Shimoda H, Baba T, Kawakami N. Prevalence, treatment, and the correlates of common mental disorders in the mid 2010's in Japan: the results of the world mental health Japan 2nd survey. J Affect Disord. 2018;241:554-62.

32. Kawakami N, Takeshima T, Ono Y, Uda H, Hata Y, Nakane Y, Nakane H, Iwata N, Furukawa TA, Kikkawa T. Twelve-month prevalence, severity, and treatment of common mental disorders in communities in Japan: preliminary finding from the world mental health Japan survey 2002-2003. Psychiatry Clin Neurosci. 2005;59(4):441-52.

33. Kessler RC, Ustun TB. The world mental health (WMH) survey initiative version of the World Health Organization (WHO) composite international diagnostic interview (CIDI). Int J Methods Psychiatr Res. 2004;13(2):93-121.

34. American Psychiatric Association. Diagnostic and Statistical Manual of Mental Disorders. 4th ed. Washington, DC: American Psychiatric Association; 1994.

35. Kessler RC, Angermeyer M, Anthony JC, De Graaf R, Demyttenaere K, Gasquet I, De Girolamo G, Gluzman S, Gureje O, Haro JM, et al. Lifetime prevalence and age-of-onset distributions of mental disorders in the World Health Organization's world mental health survey initiative. World Psychiatry. 2007;6(3):168-76.

36. Gigantesco A, Mirante N, Granchelli C, Diodati G, Cofini V, Mancini C, Carbonelli A, Tarolla E, Minardi V, Salmaso S, et al. Psychopathological chronic sequelae of the 2009 earthquake in L'Aquila, Italy. J Affect Disord. 2013;148(2-3):265-71.

37. Hirth JM, Leyser-Whalen O, Berenson AB. Effects of a major U.S. hurricane on mental health disorder symptoms among adolescent and young adult females. J Adolesc Health. 2013;52(6):765-72.

38. Tang B, Liu X, Liu Y, Xue C, Zhang L. A meta-analysis of risk factors for depression in adults and children after natural disasters. BMC Public Health. 2014;14:623.

39. Hussain A, Weisaeth L, Heir T. Posttraumatic stress and symptom improvement in Norwegian tourists exposed to the 2004 tsunami--a longitudinal study. BMC Psychiatry. 2013;13:232.

40. Wang PS, Aguilar-Gaxiola S, Alonso J, Angermeyer MC, Borges G, Bromet EJ, Bruffaerts R, de Girolamo G, de Graaf R, Gureje O, et al. Use of mental health services for anxiety, mood, and substance disorders in 17 countries in the WHO world mental health surveys. Lancet. 2007;370(9590):841-50.

41. Singer JD, Willett JB. It's about time: using discrete-time survival analysis to study duration and the timing of events. J Educ Stat. 1993;18(2):155-95.

42. Johannesson KB, Lundin T, Hultman CM, Lindam A, Dyster-Aas J, Arnberg F, Michel PO. The effect of traumatic bereavement on tsunami-exposed survivors. J Trauma Stress. 2009;22(6):497-504.

43. Ochi $S$, Murray $V$, Hodgson $S$. The great East Japan earthquake disaster: a compilation of published literature on health needs and relief activities, march 2011-september 2012. PLoS Curr. 2013;5:ecurrents.dis. 771 beae7d8f41c31cd91e765678c005d. https://doi.org/10.1371/currents.dis. 771 beae7d8f41c31cd91e765678c005d.

44. Ishii T, Ochi S, Tsubokura M, Kato S, Tetsuda T, Kato J, Nishikawa Y, Morita T, Kami M, Iwamoto $Y$, et al. Physical performance deterioration of temporary housing residents after the great East Japan earthquake. Prev Med Rep. 2015;2:916-9.

45. Moriyama N, Urabe Y, Onoda S, Maeda N, Oikawa T. Effect of residence in temporary housing after the great East Japan earthquake on the physical 
activity and quality of life of older survivors. Disaster Med Public Health Prep. 2017;11(6):701-10.

46. Carek PJ, Laibstain SE, Carek SM. Exercise for the treatment of depression and anxiety. Int J Psychiatry Med. 2011:41(1):15-28.

47. Suzuki S, Yoshihisa A, Kanno Y, Watanabe S, Takiguchi M, Miura S, Yokokawa T, Sato T, Oikawa M, Yamaki T, et al. Prognostic impact of living in temporary housing in Fukushima after the great East Japan earthquake. J Card Fail. 2017;23(1):90-2.

48. Nakaya N, Nakamura T, Tsuchiya N, Narita A, Tsuji I, Hozawa A, Tomita H. Prospect of future housing and risk of psychological distress at 1 year after an earthquake disaster. Psychiatry Clin Neurosci. 2016;70(4):182-9.

49. Suzuki Y, Kim Y. The great East Japan earthquake in 2011; toward sustainable mental health care system. Epidemiol Psychiatr Sci. 2012;21(1):711.

50. Suzuki Y, Weissbecker I. Post-disaster mental health care in Japan. Lancet. 2011;378(9788):317.

51. Kawakami N, Yasuma N, Watanabe K, Ishikawa H, Tachimori H, Takeshima T, Umeda M, Shimoda H, Nishi D. Association of response rate and prevalence estimates of common mental disorders across 129 areas in a nationally representative survey of adults in Japan. Soc Psych Psych Epid. 2020 https://doi.org/10.1007/s00127-020-01847-3.

52. Yasuma N, Watanabe $K$, Nishi D, Ishikawa $H$, Tachimori H, Takeshima T, Umeda M, Sampson L, Galea S, Kawakami N. Urbanization and internet addiction in a nationally representative sample of adult community residents in Japan: a cross-sectional, multilevel study. Psychiatry Res. 2019; 273:699-705.

\section{Publisher's Note}

Springer Nature remains neutral with regard to jurisdictional claims in published maps and institutional affiliations.

Ready to submit your research? Choose BMC and benefit from:

- fast, convenient online submission

- thorough peer review by experienced researchers in your field

- rapid publication on acceptance

- support for research data, including large and complex data types

- gold Open Access which fosters wider collaboration and increased citations

- maximum visibility for your research: over $100 \mathrm{M}$ website views per year

At $\mathrm{BMC}$, research is always in progress.

Learn more biomedcentral.com/submissions 